Dossiê

\title{
Bourdieu, Argélia e a Perspectiva Pós-Colonial ${ }^{2}$
}

Julian $\mathrm{G} 0^{3}$

Resumo: É bem sabido que as primeiras pesquisas de Bourdieu focaram na Argélia. Mas podem estas pesquisas serem classificadas como parte dos "estudos pós-coloniais"? Este ensaio retoma os primeiros escritos de Bourdieu para mostrar que ele gerou uma abordagem crítica do colonialismo que superou os limites da episteme imperial francesa. Enquanto visões convencionais do colonialismo o viam como um meio neutro para a transferência cultural, portanto, refletindo apenas as preocupações e interesses da metrópole, Bourdieu chamou a atenção para as experiências e preocupações das pessoas colonizadas para teorizar o colonialismo como um sistema social estruturado pelo racismo e pela violência, que teve importante impacto sobre o colonizador e igualmente sobre o colonizado. Neste sentido, os primeiros trabalhos de Bourdieu não eram apenas sobre o colonialismo, mas eram também epistemologicamente pós-colonial.

Palavras-chave: Bourdieu pós-colonial; Colonialismo; Bourdieu na Argélia.

\section{BOURDIEU, ALGERIA AND THE POSTCOLONIAL STANDPOINT}

Abstract: It is well known that Bourdieu's early research was on French colonialism in Algeria. This essay shows how relatively novel was his research and how

1 Artigo traduzido do original em inglês por Mariana Bombo Perozzi Gameiro. Revisão técnica de Angelo Martins Jr.

2 Algumas das ideias contidas neste artigo são também encontradas em Julian Go, "Decolonizing Bourdieu: Colonial and Postcolonial Theory in Pierre Bourdieu's Early Work." Sociological Theory 31:49-73, 2013. 
it positions Bourdieu as a postcolonial theorist of sorts. By working with local Algerian intellectuals, and by attending to the particular experiences and forms of colonialism, Bourdieu generated concepts and theory about colonialism that overcame the limits of the French imperial episteme. While dominant views in France at the time thought about colonialism as an administrative matter, thereby reflecting only the concerns and categories of colonial governmentality, Bourdieu critically theorized colonialism as a social form structured by racism and violence. His research was not just about colonialism but was also epistemically postcolonial.

Key-words: Post-colonial Bourdieu; Colonialism; Bourdieu in Algeria

\section{Introdução}

Pierre Bourdieu não é pensado frequentemente como um teórico pós-colonial. Ao contrário, seu trabalho tem sido criticado por proeminentes acadêmicos pós-coloniais, como Edward Said (1989: 223). Said está entre aqueles que repreendem Bourdieu por ocluir o colonialismo em seu trabalho (ver também CONNELL, 2007: 41-43). Claro, sabemos que Bourdieu não ignorou o colonialismo. Sua pesquisa inicial sobre os cabilas na Argélia levou a vários escritos que fizeram referência e discutiram o colonialismo francês (BOURDIEU, 1958; 1959; 1961 [1958]; BOURDIEU et al., 1963). Em tal trabalho, ele colaborou e aprendeu com importantes intelectuais argelinos, como Abdelmalek Sayad (e.g. BOURDIEU; SAYAD, 1964). Mas os últimos trabalhos teóricos de Bourdieu sobre a prática, baseados em suas pesquisas iniciais, de fato abstraíram o contexto colonial e ignoraram isso. E, na maior parte, acadêmicos europeus ou norte-americanos que leem, se referem ou ressaltam Bourdieu focam no trabalho dele sobre a França, e não em seu trabalho inicial sobre o colonialismo. Assim, críticos de Bourdieu, como Edward Said, podem ser perdoados.

O objetivo deste artigo é retornar a alguns dos escritos iniciais de Bourdieu sobre a Argélia para mostrar que o engajamento analítico de Bourdieu é muito mais profundo do que assumem seus críticos e, sobretudo, seus leitores simpatizantes. Eu mostro que Bourdieu não apenas se refere ao colonialismo em seu trabalho inicial; ele fez do colonialismo um objeto direto de estudo. De fato, Bourdieu ofereceu uma teoria nascente do colonialismo que foi inovadora para a sua época. Além disso, esta teoria do colonialismo - que analisou o colonialismo como uma forma social com lógicas distintas de racialização e violência - pode ser apropriadamente concebida como um tipo de teoria pós-colonial. Bourdieu ofereceu uma teorização crítica do colonialismo que estava enraizada 
na visão do dominado e que, por sua vez, superou os limites da episteme imperial francesa. Trabalhando com intelectuais argelinos, e observando experiências particulares e formas de colonialismo, o primeiro trabalho de Bourdieu pode ser visto como uma forma nascente de teoria pós-colonial.

Mas, primeiro, o que é "teoria pós-colonial"? Eu começo com uma rápida visão geral de seus principais elementos, antes de me voltar ao contexto imperial francês e ao lugar dos escritos de Bourdieu nele.

\section{Pensamento Pós-colonial e a Episteme do Império}

Nós podemos traçar a teoria pós-colonial na América do Norte e na Europa em dois principais estágios ou ondas. Enquanto a tendência dos estudos pós-coloniais nas humanidades emergiu nos anos 1980 e se consolidou nos anos 1990, uma versão preliminar se encontra no pensamento anticolonial do início à metade do Século XX. Esta "primeira onda" inclui pensadores como Frantz Fanon (1925-1961), Aimé Césaire (1913-2008), Amilcar Cabral (1924-1973), C.L.R. James (1901-1989) e W.E.B. DuBois (1868-1963), entre outros. Tal onda estabeleceu as bases para a segunda onda posterior da teoria pós-colonial nas humanidades que emergiu na academia do Norte. Esta segunda onda inclui Edward Said, Homi Bhabha, Gayatri Spivak, os Estudos Subalternos e Dipesh Chakrabarty, assim como, na America Latina, a escola "decolonial" de pensamento representada por Mignolo (2009), entre outros (GO, 2016).

A primeira onda da teoria pós-colonial é diferente da segunda em vários aspectos. Apesar dessas diferenças, existem muitos temas comuns, sublinhando preocupações e coordenadas compartilhadas ao longo das duas ondas. $\mathrm{O}$ próprio termo "pós-colonial" é sugestivo de algumas dessas similaridades. A palavra "pós-colonial" na expressão "teoria pós-colonial” ou em "estudos pós-coloniais" não se refere a um momento ou período histórico depois da descolonização. Ela se refere, ao invés disso, à uma posição ou postura relacional contra o colonialismo e além dele. Leela Gandhi (1998: 4) caracteriza os estudos pós-coloniais como "um projeto disciplinar dedicado à tarefa acadêmica de revisar, lembrar e, crucialmente, interrogar o passado colonial" para transcender os legados deste passado. Nesta "recuperação terapêutica do passado colonial, o pós-colonialismo precisa definir a si mesmo como uma área de estudo que pretende não apenas fazer, mas também ganhar, sentido teórico para além do passado (GANDHI, 1998: 5). Isto é o que tanto a primeira como a segunda onda compartilham, a despeito de suas outras diferenças. A teoria pós-colonial em todas as suas diferentes formas compartilha uma crítica do império, um 
reconhecimento crítico dos legados do colonialismo, e tenta imaginar possibilidades que transcendem aqueles legados.

Ainda assim, a teoria pós-colonial não apenas critica os legados político-econômicos do império. Uma de suas contribuições marcantes é focar na cultura inteira do império e seus vários legados: as formas e os processos discursivos, ideológicos, epistêmicos e psicológicos associados com o imperialismo. Esses incluem, lógico, o Orientalismo e o racismo. Eles também incluem o aparato inteiro relacionado ao conhecimento imperial e os modos de pensar que facilitaram e possibilitaram o imperialismo. Colonialismo e imperialismo eram parte e parcela de uma cultura inteira nas metrópoles ocidentais; uma cultura que incluía modos de pensar e conhecer (uma episteme) que eram produzidos pelo império e que, por sua vez, produziam o próprio império. A teoria pós-colonial, portanto, é um corpo espontaneamente coerente de escritos e pensamentos que desvela e critica as culturas do colonialismo em um esforço para transcender os limites das maneiras imperialistas de conhecer e ver.

Existem, portanto, pelo menos dois elementos centrais na teoria pós-colonial. O primeiro é que ela emerge, sobretudo, da perspectiva do colonizado. Ela está enraizada e emerge das experiências e visões do dominado. Por isso, Fanon ([1952]1967) inicia seu principal trabalho Pele Negra, Máscaras Brancas, perguntando "O que o homem negro quer?". A cultura do império emerge e reflete as experiências, interesses e visões das metrópoles dominantes. A teoria pós-colonial reflete as experiências, interesses e visões do colonizado. $\mathrm{O}$ segundo está relacionado: a teoria pós-colonial procura desvelar, criticar e ir além desta episteme imperial. A teoria pós-colonial é "pós"-colonial no sentido em que ela procura conhecimentos e enquadramentos para entender o mundo que não dependem das lentes colonialistas. A teoria pós-colonial se refere a um corpo de conhecimentos e quadros de entendimento de mundo que criticam, ao invés de aproveitar, reforçar ou reproduzir esta larga episteme do império (GO, 2016).

Quando Bourdieu iniciou seu trabalho na Argélia no fim dos anos 1950, a episteme do império francês era uma formação de conhecimento multicamadas e complexa que vinha se desenvolvendo por séculos, de acordo com o desenvolvimento do próprio império francês. Mas na metade do Século XX, uma série de eventos havia chacoalhado aquela episteme imperial e levado a uma proliferação de novos discursos. Depois de perder a Síria e o Líbano, enfrentar revolta ou conflito na Indochina e Madagascar, e esperando a erupção da resistência no Marrocos e Tunisia, o Estado imperial francês começou a ponderar questões de reprodução, e a episteme imperial da França foi então marcada por discussões sobre como melhor administrar as novas ameaças e manter o império 
(SORUM, 1977). Questões sobre "assimilação" e "associação" vinham ganhando espaço há algum tempo, mas a ameaça de revolta e as pressões globais direcionadas à descolonização forçaram a procura por novos modelos de administração e integração imperial. Na Argélia, por exemplo, o governador-geral Jacques Soustelle promoveu a ideia de "integração para fazer franceses argelinos" - uma variante da doutrina do "separado mas igual" que devia solidificar a lealdade para com o império (LE SUEUR, 2001: 23-25). A antropóloga Germaine Tillion, conselheira de Soustelle, escreveu L’Algérie en 1957 (1957) e argumentou que a população nativa da Argélia precisava de políticas de desenvolvimento esclarecidas facilitadas pela ajuda econômica francesa. Em sua opinião, a França não vinha fazendo um trabalho suficientemente bom de modernização da Argélia e suas colônias; se o fizesse, haveria menos descontentamento entre a população (TILLION, 1958; ver também SORUM, 1977: 84-87; LE SUEUR, 2001: 145-150).

Relacionado a essas questões de políticas estava um campo científico social inteiro, que vinha contribuindo para a episteme imperial há décadas. $\mathrm{O}$ Instituto de Etnologia, criado em 1925, serviu como elo-chave entre etnólogos franceses e os estados coloniais (CONKLIN, 2002; WILDER, 2003). Desde os primeiros anos do Século XX, categorias acadêmicas tinham sido implícitas ou explícitas sobre a prática do colonialismo francês. Debates sobre "aculturação" e assuntos relacionados à mudança da cultura eram convocados nos debates a respeito de se a política francesa deveria integrar temas colonizados e se isso seria de fato possível. A teoria da modernização nos anos 1940 foi recrutada para apoiar o colonialismo francês. $O$ trabalho de Tillion pedindo por políticas de desenvolvimento mobiliza implicitamente, se não explicitamente, a teoria da modernização. E a insistência antropológica sobre grupos étnicos como unidade-chave de análise foi empregada para apoiar o modelo de integração, mesmo que ela pudesse também ser usada como ponto inicial para justificar o modelo de assimilação (COOPER, 2002). Todo esse discurso carregava assumpções etnológicas sobre culturas "nativas" e estavam engatadas em conceitos teóricos como "modernização", "urbanização", "grupos étnicos" e "aculturação".

À luz deste discurso, os trabalhos de Frantz Fanon e Aimé Césaire, entre outros no império, foram audazes, inovadores e seminais. Expressando o ponto de vista do dominado, criticaram o colonialismo por suas contradições, racismo e violência. A esses pensadores se juntaram outros críticos na metrópole; críticos que, enquanto escreviam na metrópole, eram capazes de pensar o colonialismo do ponto de vista do dominado também. Com o passar dos anos 1950, e especialmente com a erupção da guerra da Argélia, intelectuais franceses proeminentes, como Albert Camus, Jean-Paul Sartre e Raymond Aron, todos 
criticaram o império francês (LE SUEUR, 2001: 135-40). Além disso, na ciência social, o antropólogo Michel Leiris (um dos fundadores, com Jean-Paul Sartre, de Les Temps Modernes - revista Tempos Modernos) e seus seguidores foram importantes por articular novas críticas da episteme imperial. Eles ofereceram os primeiros desafios à antropologia francesa e às amarras dela à administração colonial (Leiris, 1950).

Emergindo de todas essas discussões mais críticas estava um novo modo de pensar sobre o colonialismo. $\mathrm{O}$ discurso colonial francês tendia a ver o colonialismo de uma maneira muito estreita. Eles o pensavam como um portador neutro da política e da civilização francesa. Esta noção era um aspecto vital da episteme imperial, porque ela justificava o colonialismo francês. Mas esta noção de colonialismo falhava em vê-lo como uma força autônoma distinta de si mesmo. Como nota, em Cooper (2002) os estudos coloniais propriamente ainda não tinham emergido - o que significa que teorias e pesquisas que tratavam $o$ colonialismo como um objeto social em si mesmo, como uma força ou estrutura que impactava as relações sociais de modo notável, ainda não tinham nascido.

O pensamento pós-colonial inicial de Fanon ([1952]1967) ou Césaire (1955), e o pensamento anticolonial de escritores na metrópole francesa, ajudaram a gerar e promover esta ideia alternativa de colonialismo como um sistema ou forma em si próprio. Houve muitas variantes. Por exemplo, O. Mannoni, Albert Memmi e Fanon, cada um foi além do foco tradicional da etnologia sobre aculturação e grupos étnicos e teorizou o colonialismo como um modelador das interações sociais e, por fim, da psique. A Psychologie de la colonization (1964 [1950]) - Psicologia da colonização - de Mannoni, foi seminal aqui (LANE, 2002). Discutindo a Madagascar francesa, Mannoni insistiu no colonialismo como "um caso do encontro de dois tipos inteiramente diferentes de personalidade" que envolviam novas relações que "nunca tinham sido apropriadamente analisadas" (MANNONI, 1964 [1950]: 17). Ao invés de reduzir as reações e práticas "nativas" a uma "mentalidade primitiva", Mannoni argumentou que elas deviam ser entendidas dentro do contexto da "situação colonial" que impacta o colonizador e o colonizado igualmente (ibid). Similarmente, Memmi (1957) pensou o colonialismo como constituído por uma relação básica de colonizador-colonizado que, por sua vez, deu forma às identidades de ambos. Enquanto a ideologia colonial francesa da assimilação prometia igualdade, o colonialismo sempre reteve a igualdade; e assim os colonizados são consistentemente lembrados de suas incorrigíveis diferenças frente ao colonizador. Os colonizados são outorgados com um complexo de inferioridade e então são compelidos a 
desautorizar sua cultura tradicional. Por outro lado, o colonizador adota a identidade de superioridade, combinando sua posição estrutural dominante.

As análises de Mannoni e Memmi eram originais porque, enquanto focavam no impacto psicológico do colonialismo, também teorizavam o colonialismo como "uma sociedade de um tipo", ou seja, como um objeto em si mesmo, digno de investigação (ibid, 7). $\mathrm{O}$ antropólogo Michel Leirus promoveu uma ideia muito similar. Ele afirmava que a obsessão da etnologia com grupos étnicos primitivos e sociedades intocadas pelo mundo estrangeiro era fatalmente danosa. O colonialismo mesmo construiu as assim chamadas sociedades "nativas". Leiris similarmente argumentou que a oclusão da temporalidade por parte da etnologia era problemática. Como sociedades "nativas" passam pela regra colonial, elas não são estáticas como a etnologia presumia, mas, sim, completamente históricas. Leiris então reconhecia o colonialismo como uma força que impelia as lógicas sociais e a própria história (LEIRIS, 1950).

Georges Balandier, um dos estudantes de Leiris, levou a ideia ainda mais adiante. Seu The Colonial Situation (A Situação Colonial) famosamente fez das sociedades coloniais um objeto de análise. Como Leiris, Balandier reconheceu as conexões entre antropólogos e o colonialismo, cobrando os antropólogos por terem "evitado (inconscientemente na maioria dos casos)" as realidades do colonialismo e suas próprias inserções nele (BALANDIER, 1966 [1951]: 56). BALANDIER então se apoiou em Marcel Mauss e Max Gluckmann para criticar a insistência antropológica existente e ofereceu uma sociologia do colonialismo que ameaçou a situação colonial como um "complexo único"; uma "totalidade" (BALANDIER, 1966 [1951]: 22, 42; COOPER, 2002; ver também SAADA, 2002). Aqui ele emprestou a noção de "situação colonial" de Mannoni, mas foi crítico da redução que Mannoni faz do colonialismo à uma "má-compreensão" psicoanalítica ([1951]1966: 36). Balandier argumentou que o colonialismo deveria ser tratado como uma "totalidade de relacionamentos entre pessoas coloniais e poderes coloniais e entre as culturas de cada um deles" (57; também 21, 55).

\section{A entrada de Bourdieu}

Esses escritores que eram críticos do colonialismo francês, que desafiaram as etnologias coloniais e simultaneamente teorizaram o colonialismo como uma força em si com poderosos efeitos, todos qualificaram as instâncias do nascente pensamento pós-colonial. Eles desafiaram e então contornaram a episteme imperial francesa, oferecendo análises alternativas e críticas do colonialismo. Este foi o contexto intelectual no qual Bourdieu fez seu trabalho. Ele não estava, 
claro, alheio aos debates sobre o colonialismo. Na época que ele estudou em Paris, no fim dos anos 1940 e início dos 1950, Leiris e Balandier já estavam oferecendo suas críticas à etnografia colonial. Bourdieu, mais tarde, se referiria a ambos em seu trabalho. Bourdieu também se engajou com ou leu Aron, Tillion e Sartre (BOURDIEU, 1990: 7; 2003: 18). Ele também leu os trabalhos iniciais de Fanon, como discutirei brevemente. Além disso, Bourdieu mesmo era parte do aparato colonial e seu complexo conhecimento. Ele foi enviado para a Argélia em 1955 para o serviço militar, posteriormente desempenhando tarefas administrativas numa base aérea e depois no escritório do serviço de informação em Argel. Lá ele leu Tillion e outros e sondou o arquivo colonial para obter informações que formariam a base de seu trabalho The Algerians (1958 [1962]). La, também, ele conheceu praticamente todos que fizeram trabalho acadêmico na Argélia, incluindo etnógrafos e administradores coloniais (HEILBRON, 2011: 185; SAYAD, 2002: 59-68).

Bourdieu ensinou na Universidade de Argel depois do serviço militar, onde ele foi exposto aos "orientalistas" e intelectuais pró-império (YACINE, 2008b: 25-28). Algumas dessas figuras eram parte da mesma antropologia colonial atacada por Leiris (BOURDIEU, 2000: 8). Durante este tempo, Bourdieu também conduziu pesquisa de campo colaborativa, financiada pela ARDES (Associação para Pesquisa Demográfica, Econômica e Social) que era o braço argelino do INSEE francês (Instituto Nacional para Estatísticas e Estudos Econômicos) (SEIBEL, 2004). Disso viria muito de seu outro escrito sobre a Argélia e suas experiências colaborativas formativas que, conforme Heilbron (2011) mostra, ofereceriam um modelo para seus trabalhos posteriores, mas que também o impulsionariam mais fundo nos assuntos intelectuais e debates sobre o colonialismo francês. Os colaboradores e colegas de pesquisa de Bourdieu incluíam estudantes, jornalistas, acadêmicos independentes e intelectuais argelinos como Mouloud Feraoun e Moloud Mammeri, os quais provavelmente expuseram mais Bourdieu ao discurso crítico sobre o colonialismo francês e que escreveram, eles mesmos, suas próprias visões sobre o colonialismo na Argélia (YACINE, 1990). Feraoun, um romancista que ajudou a criar um gênero de "romances etnográficos", leu e comentou sobre o primeiro trabalho de Bourdieu sobre os cabilas (BOURDIEU, 2001: IX; YACINE, 2008b: 40). Outro colaborador de Bourdieu, Abdelmalek Sayad, seria o co-autor de Bourdieu em Le déracinement (O desenraizamento, 1964) e seria um importante amigo e uma influência intelectual sobre ele (BOURDIEU, 1998; 2008b; SAYAD, 2002).

Neste contexto, Bourdieu veio a articular sua própria nova teoria sobre o colonialismo que, como eu mostrarei agora, teorizou o colonialismo de um modo 
que desafiou a episteme imperial. Bourdieu, assim, se uniu a figuras como Leirus, Balandier e Fanon - e foi mesmo além deles.

\section{Colonialismo como um sistema}

A teorização de Bourdieu sobre o colonialismo veio em seu primeiro grande trabalho, Sociologie de l'Algérie (Sociologia da Argélia, 1958). Aqui, Bourdieu se apoia nas ideias existentes sobre a sociedade colonial e a situação colonial. Ele argumenta que o colonialismo é um sistema em si mesmo. A "sociedade colonial", ele escreve, "é um sistema cuja necessidade e lógica interna é importante entender" (120). Este foi um uso direto das ideias de Balandier e Leiris. De fato, em seu trabalho subsequente, "Le Choc des civilisations" (O choque das civilizações, 1959), Bourdieu cita Balandier para criticar Tillion em referência ao termo "a situação colonial". Bourdieu também postula que o colonialismo é uma força constitutiva, mais do que um meio neutro para transmitir a "civilização" francesa, criticando os estudos coloniais antropológicos. Esses estudos negligenciaram a influência colonial sobre culturas nativas supostamente intocadas: "nunca existiu na Argélia uma comunidade verdadeiramente isolada, completamente intocada pela situação colonial" (BOURDIEU, 1959: 63). Do mesmo modo, tanto em "Le Choc des civilisations" e Algeria 1960 ele ataca a teoria da modernização por negligenciar o colonialismo e seu efeito sobre a economia. A teoria da modernização falha, ele argumenta, porque ela oculta um "exame sistemático da influência que as transformações [econômicas coloniais] têm sobre o sistema de relações e disposições sociais" (BOURDIEU, 1979 [1963]: 30).

Por outro lado, Bourdieu não apenas se apoiou nas abordagens críticas existentes sobre o colonialismo. Ele também inovou em vários aspectos. Primeiro, ele teorizou o colonialismo como uma "relação de dominação" estruturada como um "sistema de casta". O colonialismo envolvia "segregação racial" que fez a sociedade colonial "maniqueísta em forma" (1961 [1958]: 120, 132-134). Classe social é menos importante do que raça. De acordo com Bourdieu, o racismo era uma mera legitimação do colonialismo: "a função do racismo não é outra que oferecer uma racionalização do estado existente de coisas, de modo a fazer com que ele pareça ser uma ordem instituída legalmente" (ibid: 133). Segundo, Bourdieu teoriza o sistema de dominação racial como fundado na coerção. Argumentando contra a sugestão implícita na teoria da modernização de que a modernização ocorre por "escolha", Bourdieu destaca como no colonialismo "o exercício do poder de escolha, que teoricamente pertence àquelas sociedades que confrontam uma a outra, não foi concedido à sociedade dominada" (ibid: 
120; ver também BOURDIEU, 1979 [1963]: 32). Bourdieu mostrou como as políticas francesas desde a Senatus Consulte 4 de 1863 levaram a uma "vivissecção social” da Argélia francesa (120-121). Bourdieu então concluiu que a base da dominação colonial é a força nua. A guerra pela independência expôs "a verdadeira base para a ordem colonial: a relação, apoiada na força, que permite à casta dominante manter a casta dominada em uma posição de inferioridade". Ele adicionou: "repressão pela força combina perfeitamente com a coerência lógica do sistema [colonial]" (1960 [1958]: 146).

Esta teorização do colonialismo como um sistema racializado de dominação enraizado na coerção foi além das abordagens de Mannoni e Memmi porque Bourdieu sublinhou o monopólio sobre a violência do Estado colonial. Nem Mannoni nem Memmi teorizaram a violência como intrínseca ao sistema. Além disso, a explicação de Bourdieu sobre privilégio racial e força nua como a base do sistema foi além das teorizações iniciais de Leiris e Balandier sobre a "situação colonial". Enquanto nem Leiris ou Balandier teriam negado a importância do racismo ou da coerção, eles não fizeram do privilégio racial e da coerção elementos centrais para suas teorias do sistema colonial.

Mas por que Bourdieu estava apto a privilegiar racismo e força em sua teoria do colonialismo, se nem Leiris e Balandier o fizeram? Isso pode ser porque Bourdieu, diferentemente de Leiris e Balandier, escreveu após o tumultuo revolucionário de meados dos anos 1950 e a repressão violenta que seguiu, e suas experiências pessoais neste contexto devem ter parcialmente inspirado sua teorização. Em outras palavras, como a maioria dos teóricos pós-coloniais, Bourdieu adotou o ponto de vista do dominado no sentido que sua teoria foi construída sobre as experiências e preocupações do colonizado. Ele lembrou como, em sua viagem como soldado na Argélia, ele ficou impressionado com o racismo de seus companheiros de guerra, muitos dos quais tinham vindo de outra colônia francesa, a Indochina. O racismo deles implicava, ele dizia, uma "visão de mundo" inteira (BOURDIEU, 2008b: 38). Bourdieu viu este racismo do ponto de vista dos argelinos mesmos. Adicionalmente, o trabalho de campo de Bourdieu tornou palpável a brutalidade do regime colonial francês. $\mathrm{O}$ "sofrimento das pessoas" realocado pelo Estado colonial francês, ele escreveu mais tarde, o moveu profundamente; e muitos desses sofrimentos ele tentou capturar com sua câmera (2003: 18). Por meio de seu trabalho de campo, ajudado por muitos colaboradores argelinos locais, ele também encontrou os horrores do aparato de força dos colonizadores. Ele depois lembrou da descrição de 
um camponês sobre a tortura infligida pelo exército francês (2004: 48). E seus próprios colaboradores e amigos, como Moulah Hennine (a quem ele e Sayad dedicaram Le Déracinement) e Mouloud Feraoun (BOURDIEU, 2001: IX) foram assassinados pelo grupo de direita do exército, os "contra-terroristas" OAS (Organisation de l'armée secrète - organização do exército secreta). Essas e outras experiências, ele escreveu posteriormente, "profundamente me balançaram, ao ponto de às vezes voltarem nos meus sonhos" (BOURDIEU, 1998: 9; 2001: IX; 2008b: 359; citações de 2004: 48). Bourdieu mesmo temia ameaças de morte dos advogados de direita do regime dos colonos. As ameaças o levaram a retornar à França (YACINE, 2004: 492). Este foi um sistema inteiro de dominação e coerção que Bourdieu testemunhou pessoalmente - e sobre o qual ele teorizou em seus primeiros escritos.

Neste sentido, não é inteiramente surpreendente que as opiniões de Bourdieu a respeito do colonialismo, raça e violência se aproximem das de Fanon (1968[1961]). De todos os novos teóricos coloniais, Fanon era provavelmente o mais explícito sobre o caráter violento do colonialismo. Os "agentes do governo [colonial]", ele escreveu, "falam a língua da força pura" (1958 [1961]: 38). Ainda, os livros de Fanon Os Condenados da Terra (1961) e A Dying Colonialism (1965[1959]) foram publicados depois que Bourdieu escreveu Sociologie de lalgérie (1958). Pele Negra, Máscaras Brancas, de Fanon, foi publicado em 1952, mas naquele trabalho Fanon diz comparativamente pouco sobre o colonialismo como um objeto em si mesmo. Se houve alguma coisa, o mais provável é que $A$ Dying Colonialism de Fanon tenha influenciado a teorização de Bourdieu sobre o colonialismo como sendo baseado na violência (o livro foi publicado antes do ensaio de Bourdieu The Revolution within the Revolution - A revolução dentro da revolução -, onde Bourdieu articulou a maioria da sua teorização sobre o sistema colonial). Como nota em Haddour (2010: 77), Bourdieu provavelmente tirou bastante de Fanon no que diz respeito ao caráter racial do colonialismo, a natureza da violência e o impacto do colonialismo (ver também LANE, 2000: 18). Ainda assim, a teorização de Bourdieu não foi simplesmente mimética. Fanon, em A Dying Colonialism, estava muito mais interessado em teorizar o efeito psicológico do colonialismo e da revolução anti-colonial do que em teorizar a natureza do colonialismo em si mesma. A teorização de Bourdieu do colonialismo como uma "relação de dominação" em fim baseada na coerção nua - e tendo suas próprias e distintas lógicas - era mais explícita como uma teoria do colonialismo. Como Bourdieu mesmo insistiu, a sua era uma sociologia do colonialismo enraizada na então chamada análise "objetiva", e não um ensaio 
psicológico, filosófico ou político tipicamente associado ao "novo humanismo" de Fanon (ALESSANDRINI, 2000; LE SUEUR, 2001: 250).

\section{Interacionismo Colonial}

A teorização de Bourdieu do colonialismo como um sistema de dominação racializada enraizada na força também carregava outros elementos-chave dignos de nota. Em primeiro lugar, a afirmação de Bourdieu de que o colonialismo é um sistema que molda as interações sociais, os significados e a identidade. $\mathrm{Na}$ análise de Bourdieu, as interações sociais e seus concomitantes processos simbólicos assumem uma forma particular no colonialismo, de modo que a "situação colonial... é o contexto em que todas as ações devem ser julgadas" (1958: 149). Este era um interacionismo proto-simbólico que era muito mais estruturalista do que a sua posterior encarnação sob a forma de interacionismo simbólico americano (BLUMER, 1969). As interações não são apenas determinadas pelas intenções ou significados contingentes dos atores, mas pelo contexto colonial maior (a "situação") em que se desenrolaram.

Bourdieu aqui elabora sobre os temas seminais levantados por Mammoni e Memmi. Conforme observado, Mannoni argumentou que as atitudes e comportamentos do colonizado poderiam ser melhor compreendidos no contexto da relação colonial. Como os colonizados haviam sido arrancados de sua existência anterior e não tinham outra opção senão confiar no novo poder colonizador, eles eram psicologicamente dependentes do colonizador. A dependência manifestou-se em vários tipos de comportamento que, retirados do contexto, pareciam irracionais e reafirmavam os estereótipos racializados (MANNONI, 1964 [1950]). Bourdieu, ao contrário de Mannoni, não viu a psique como o mecanismo causal fundamental da ação, mas compartilhou com Mannoni a ideia de que a estrutura colonial molda comportamentos e interações. Bourdieu argumenta que o sistema colonial implica em papéis distintos e logicamente necessários para o colonizador e para o colonizado: ao primeiro, o colonialismo demanda racismo e paternalismo, ao segundo, subserviência e a adoção de comportamentos estereotipados relacionados. O sistema colonial na Argélia obrigou os argelinos a "desempenhar o papel do árabe como visto pelo francês" (1961 [1958]: 161, ver também LOYAL, 2009).

Em sua introdução a Travail et travailleurs en Algérie (Trabalho e trabalhadores na Argélia), Bourdieu vai mais longe, afirmando que a relação de subordinação formal significa que os colonizados são forçados a estar excessivamente atentos às ações e expressões dos colonizadores. Porque eles são dependentes, 
eles precisam estar consistentemente em sintonia com "palavras ou gestos" que "parecem para nós sobretudo convencionais - cumprimentos, apertos de mãos, sorrisos", mas que para os colonizados podem ser "sinais de reconhecimento" (BOURDIEU et al., 1963: 264; BOURDIEU; ROBBINS; GOMME, 2003: 16). Isso explica o estereótipo de que os colonizados são irracionalmente sensíveis. A "sensibilidade famosamente atribuída aos argelinos e às pessoas colonizadas em geral é um produto do sistema colonial - mais precisamente da desigualdade nas relações entre colonizadores e colonizados" (BOURDIEU; ROBBINS; GOMME, 2003: 18, fn. 20). Bourdieu aceita assim a compreensão de Mannoni de os colonizados agindo como "dependentes" frente ao colonizador. De fato, essa dependência é construída na estrutura do colonialismo: “...o sistema colonial pode funcionar corretamente se a sociedade dominada estiver disposta a assumir a natureza negativa ou 'essência' (o "árabe" não pode ser educado, é incauto, etc.) que a sociedade dominadora sustentar para ela como seu destino" (BOURDIEU, 1961 [1958]: 134). Mas Bourdieu acrescenta à Mannoni a ideia de que a mesma estrutura do colonialismo também produz hostilidade. A estrutura colonial convidou os colonizados a imitar e desejar o colonizador, mas "tornou realmente impossível imitar ou se igualar ao europeu". Assim, enquanto os argelinos agiam de forma subserviente, a "resposta deles ao paternalismo protetor europeu era assumir uma atitude de dependência tingida com agressividade" (ibid: 161).

Novamente, as experiências do trabalho de campo do próprio Bourdieu provavelmente serviram de fonte para suas ideias, permitindo que ele visse de perto as experiências e preocupações dos colonizados. Em sua seção sobre metodologia em Travail et travalleurs en Algérie (1963: 257-268), Bourdieu escreve sobre as dificuldades de fazer trabalho etnográfico em uma situação colonial exatamente porque o colonialismo é uma "relação de dominação" e, portanto, os sujeitos das entrevistas viam os entrevistadores franceses de forma diferente do que os entrevistadores argelinos (258, 159-162).

No entanto, a teoria de Bourdieu sobre o interacionismo colonial não era apenas sobre apreender interações de nível micro. Ela também conceituou dinâmicas macro coloniais. Primeiro, a hostilidade sentida por parte do colonizado devido à estrutura colonial, em última análise, gera revolução. Depois de notar como os colonizados são forçados a agir de forma subserviente, entretanto com um "toque de agressividade", Bourdieu afirma que "a situação colonial cria assim a pessoa "desprezível", ao mesmo tempo em que cria a atitude desprezível; mas cria, por sua vez, um espírito de revolta contra esse desprezo, e assim a tensão que rasga toda a sociedade em pedaços continua aumentando" (BOURDIEU, 
1961 [1958]: 134). Incidentes de hostilidade interpessoal são meros portadores de algo maior que virá. Além disso, a relação de dominação e a agressividade como resposta significam que não há esperança de reconciliação. "Porque todas essas ações são estabelecidas no contexto do sistema colonial, as relações entre as pessoas sempre aparecem contra um fundo de hostilidade que separa grupos e ameaça constantemente ressurgir para corromper o significado e a própria existência da comunicação" (BOURDIEU et al., 1963: 264; BOURDIEU; ROBBINS; GOMME, 2003: 16). Até mesmo as melhores intenções do colonizador para reformar o colonialismo ou se envolver nas chamadas "missões civilizadoras" não têm esperança. Pois, dada a estrutura colonial, esses atos invariavelmente falharão. Todos os "atos benevolentes ou generosos" são interpretados pelos "membros da sociedade dominada... à luz da relação de dominação que existe entre as duas sociedades" (BOURDIEU, 1961 [1958]: 148). Obviamente, isso representa um dilema para os "europeus anticoloniais" cuja "boa vontade" é limitada a ter efeitos negativos dada a realidade das relações de poder do colonialismo (ibid: 149, fn. 4). Aqui, a sociologia do colonialismo de Bourdieu novamente voltou a falar com os reformadores coloniais franceses e defensores do colonialismo desenvolvimentista, como Tillion. Como esses reformadores falharam em apreender a estrutura determinada do colonialismo e seu profundo impacto sobre as interações sociais e a comunicação, eles não conseguiram ver a inutilidade de seus esforços mais bem-intencionados.

\section{Colonialismo e Cultura}

Outra área dos estudos coloniais para a qual Bourdieu contribuiu foi identidade e cultura colonial. O pensamento de Bourdieu sobre identidade e cultura colonial foi parcialmente uma crítica das teorias da modernização tradicional e "aculturação" que foram dominantes na antropologia desde os anos 1930 (ROBBINS, 2005: 16-20). Bourdieu cobra essas teorias por negligenciarem a "situação colonial” na qual a cultura operava (BOURDIEU, 1959: 61). Especificamente, ele critica os estudos existentes por falharem em ver a situação colonial como um todo social - incluindo relações econômicas e relações culturais igualmente. Bourdieu ataca a abordagem da modernização e da aculturação por "autonomizar certos níveis de realidade social", transformando tudo num problema de "cultura", e negligenciando as "transformações econômicas" durante o colonialismo (BOURDIEU, 1979 [1963]: 30). Em Sociologie de l’Algérie, Bourdieu rastreia aquelas transformações socioeconômicas, mostrando como políticas coloniais a respeito de terra e trabalho criaram "uma ruptura completa e radical do toda 
a cultura" (1961 [1958]: 119), significando uma "desintegração sistematicamente induzida" (ibid: 129). Essas transformações durante o colonialismo tiveram efeitos não apenas econômicos mas também culturais, servindo para reestruturar inteiramente "o sistema de relações e disposições sociais" do colonizado (BOURDIEU, 1979 [1963]: 30). Arrancados da terra e então de seus modos de vida tradicionais, o campesinato colonial enfrenta a entrada no novo sistema de alienação capitalista das relações sociais. Portanto, "uma relação impessoal entre capital e trabalho" ameaça substituir a agricultura tradicional, mas não completamente. Em outras palavras, a economia colonial significa que dois mundos existem lado a lado: um sistema "impessoal e abstrato" de valor monetário e "os valores anteriores de prestígio e honra” (1961 [1958]: 144).

Em Le Choc des civilisations (O choque das civilizações), Bourdieu se refere a isso como uma "dualidade das regulações sociais" trazida pela introdução da cultura dos colonizadores (BOURDIEU, 1959: 59). Em seu trabalho posterior com Sayad, Bourdieu continua este tema com o conceito de "sabir cultural". O sabir é pego entre dois mundos; "dois universos mutuamente alienantes" (BOURDIEU; SAYAD, 1964: 164). Bourdieu argumenta, da mesma forma, que o colonialismo violentamente cria novas identidades conflitantes e culturas híbridas: o campesinato colonizado é forçado a se mover entre seu leque tradicional de disposições, enraizadas na agricultura de subsistência, e as novas relações de valor abstrato e impessoal. Com isso, ele oferece uma nova abordagem para se pensar sobre a cultura no colonialismo - uma abordagem que alimenta sua crítica sobre os estudos antropológicos existentes ligados à modernização e aculturação. Como "a própria lógica do colonialismo", escreve Bourdieu com Sayad (1964: 161), "produziu um novo tipo de homem e mulher", segue-se que as teorias simplistas de cultura e aculturação dos antropólogos não são suficientes. A cultura é fraturada e incompleta. Os colonizados não se tornam "modernizados" ou "aculturados", mas são "condenados... às interferências e incoerências que fazem um sabir cultural" (BOURDIEU; SAYAD, 1964: 168).

O modelo de culturas coloniais de Bourdieu aqui facilita a sua crítica das visões romantizadas da esquerda sobre o campesinato revolucionário - não menos importante, os pontos de vista de Fanon e Sartre (ver também LANE, 2000: 18-19; LE SUEUR, 2001: 252-254). Se o resultado da intrusão colonial não é uma identidade colonizada totalmente assimilada ou "aculturada", como os teóricos da modernização defenderiam, também não é uma consciência revolucionária moderna que olha adiante, como Fanon insistiu. Em vez disso, a estrutura do colonialismo e suas transformações econômicas associadas criam identidades divididas que induzem confusão e "angústia" para aqueles que a experimentam: 
O homem entre dois mundos... está exposto aos conflitos criados pelo enfraquecimento dos sistemas tradicionais de sanções e pelo desenvolvimento de um duplo conjunto de padrões morais... Este homem, lançado entre dois mundos e rejeitado por ambos, vive uma espécie de vida interior dupla, é uma presa para a frustração e o conflito interno, com o resultado de estar constantemente sendo tentado a adotar uma atitude de sobreidentificação desconfortável ou de um negativismo rebelde (BOURDIEU, 1961 [1958]: 144).

Enquanto a revolução pode ser um resultado necessário do colonialismo, o tipo de consciência revolucionária presumida por Fanon ou Sartre para estar presente entre os colonizados (ou seja, a consciência socialista avançada) não o é.

Novamente, ao formular essas ideias, as experiências de trabalho de campo de Bourdieu foram cruciais, permitindo-lhe ver melhor as experiências e as preocupações dos colonizados. "Eu fui frequentemente ajudado em meu trabalho de campo", lembra, "...por tais personagens... que [ocuparam] um lugar ambíguo entre duas condições sociais" (BOURDIEU, 2008a: 56-7). Suas interações com intelectuais locais como Mammeri também devem ter sido produtivas: 0 famoso segundo romance de Mammeri, Le Sommeil du Juste (1955, O sono do justo), narra a história de um personagem semelhante a um sabir que está preso entre a sociedade argelina tradicional e uma nova modernidade pós-colonial. E seu colaborador e amigo Feraoun estava escrevendo ao mesmo tempo sobre as ansiedades associadas com ser um híbrido cultural preso entre culturas (LE SUEUR, 2005: 25-26).

Em suma, ao formular sua abordagem inovadora sobre o colonialismo e a cultura, Bourdieu adotou implicitamente o ponto de vista do colonizado novamente. Isso, por sua vez, facilitou sua crítica à teoria antropológica da modernização/ aculturação: um discurso-chave dentro da episteme imperial. Enquanto os estudos de aculturação postulavam uma transição simples e quase feliz de um estágio de cultura para outro, o modelo de Bourdieu captura as rupturas, ambivalências e tensões causadas pelas transformações culturais induzidas pelo capitalismo colonial. Sua análise oferece, portanto, uma importante correção sociológica para a teoria da modernização/ aculturação, mostrando tanto uma complexidade das culturas quanto como o colonialismo cria as "condições econômicas e sociais de sua formação e expressão" (como Bourdieu coloca em Argélia, 1960: 30-31).

Bourdieu, por fim, articulou o modelo processual das culturas coloniais, superando assim os modelos de aculturação oferecidos pela antropologia e as análises da situação colonial de Balandier. Os estudos de aculturação convencionais 
(mainstream) teorizaram os processos culturais como estágios de conflito, ajuste, sincretismo e depois assimilação (BALANDIER, 1966 [1951]: 51; REDFIELD; LINTON; HERSKOVITS, 1936). O modelo de Bourdieu, em contraste, teorizava uma nova subjetividade entre os colonizados. Embora Bourdieu fosse crítico da romantização de Fanon sobre o campesinato revolucionário pós-colonial, ele teorizou, no entanto, como a cultura colonial ajudou a criar as condições para o novo trabalho cultural durante a revolução anticolonial. O camponês, arrancado da terra e vivendo "entre dois mundos", passa por um despertar. Sob o colonialismo, tudo o que o camponês tinha assumido como parte de sua "tradição" é lançado sob nova luz. Este "homem entre dois mundos" está "constantemente enfrentando formas alternativas de comportamento por meio da intrusão de novos valores e, portanto, se vê obrigado a fazer um exame consciente das premissas implícitas ou padrões inconscientes de sua própria tradição" (BOURDIEU, 1961 [1958]: 144). Bourdieu diferencia entre o "tradicionalismo da sociedade tradicional" (também conhecido como "tradicionalismo tradicional") e o "tradicionalismo colonial". O primeiro se refere às rotinas, símbolos e significados aceitos - às "tradições" - das pessoas que são considerados "normais" e "naturais" (ibid: 156). O segundo, provocado pela revolta sistematicamente imposta pelo colonialismo, força os colonizados a refletir sobre essas "tradições" e a enfrentar novas opções. Com a regra colonial vem a "consciência e o conhecimento de outras possibilidades"; "a descoberta da existência de outra tradição leva a uma nova compreensão da própria tradição como sendo apenas uma entre várias, ou em outras palavras, como sendo tão convencional e arbitrária quanto todas as demais" (ibid: 156).

Em The Revolution within the Revolution (A revolução dentro da revolução), Bourdieu discute como a revolução argelina manifestou essa consciência e a implantou. Os antigos símbolos e práticas, anteriormente não reconhecidos como tradição, não são apenas "descobertos"; eles também são, da mesma forma, disponibilizados para significados e funções novos. Anteriormente pré-assumidos e, portanto, escondidos, podem ser redistribuídos e retrabalhados. Exemplos incluem o véu e a checia; exemplos provavelmente tirados da discussão de Fanon sobre o véu (HADDOUR, 2010). Tanto o véu como a checia "tinham sido no contexto tradicional meros detalhes vestimentários dotados de um significado quase esquecido, elementos simples de um sistema de símbolos inconscientemente concebido. Na situação colonial, no entanto, assumem a função de sinais que são conscientemente utilizados para expressar resistência à ordem estrangeira e aos valores estrangeiros, bem como para atestar fidelidade ao seu próprio sistema de valores" (BOURDIEU, 1961, 1951): 156). Além disso, a 
revolução também permite aos colonizados adotar os símbolos dos colonizadores com uma nova agência. Agora cientes de sua própria diferença, conscientes de sua própria "cultura" de um modo que não tinham estado antes, cada "argelino pode a partir de agora assumir a plena responsabilidade por suas próprias ações e pelos empréstimos generalizados que ele fez da civilização ocidental; ele pode até mesmo negar uma parte de sua herança cultural sem negar a si mesmo no processo" (ibid: 157). Os colonizados agora podem "adotar as técnicas e instituições introduzidas pelo colonizador sem aceitar a posição de colonizado" (ibid: 162). No caso, a consciência dupla ou a identidade dividida, condenando previamente o "homem entre dois mundos" à uma angústia perpétua, podem se tornar uma ferramenta, se não uma fonte de libertação nacional.

\section{Condusão: Bourdieu e a Sociologia Pós-Colonial}

Bourdieu cresceu em proeminência no mundo intelectual de língua inglesa durante os anos 1980 e início da década de 1990 (SALLAZ; ZAVISCA, 2007). Este foi exatamente o momento em que os "estudos coloniais" e os "estudos pós-coloniais” nos EUA também cresceram (COOPER, 2005; GHANDI, 1998). E à medida que os estudos coloniais e a teoria pós-colonial se espalhavam, a sociologia enfrentava novas críticas. Acadêmicos trabalhando ou inspirados pelos estudos pós-coloniais miraram na sociologia por ocluir a história do imperialismo e do colonialismo; por reproduzir as estruturas epistêmicas imperiais e o eurocentrismo; e por falhar em fornecer uma crítica do colonialismo ocidental e da dominação racial (CONNELL, 2006; GO, 2016).

Como já notado, o trabalho de Bourdieu faz parte do corpus sociológico que sofre a crítica pós-colonial. Mas este ensaio argumentou que o trabalho de Bourdieu não deveria ser lançado sob esta luz. Wacquant lamenta os "entendimentos parciais e fraturados" do trabalho de Bourdieu (WACQUANT, 1993: 238). Enquanto isso, certamente se aplica ao modo como os estudiosos receberam o pensamento de Bourdieu sobre mudança e determinismo (STEINMETZ, 2011; SWARTZ, 1997: 113-115), também se aplica aos primeiros trabalhos de Bourdieu sobre colonialismo, dominação racial e a interação intercultural. Os trabalhos posteriores de Bourdieu, de fato, evitaram essas questões, optando, ao invés disso, por abstrair a sociedade argelina de sua história de colonialismo, visando teorizar sobre habitus, campo, capital simbólico e outros temas pelos quais Bourdieu se tornaria reconhecido. Mas seu trabalho inicial baseado na Argélia colonial colocou o colonialismo à frente e no centro. Ele teorizou sobre dominação colonial, coerção, privilégio racial e a cultura como parte de um sistema 
colonial abrangente. Essas inovações foram permitidas devido ao seu método de adotar o ponto de vista do colonizado. Nesse sentido, os primeiros trabalhos de Bourdieu também devem ser vistos como parte e não como alvo de um novo projeto que avança uma sociologia pós-colonial para ultrapassar o conhecimento sociológico eurocêntrico.

\section{Referências}

ALESSANDRINI, A. C. Humanism in Question: Fanon and Said. In: A Companion to Postcolonial Studies, edited by H. Schwarz and S. Ray. Malden, MA: Blackwell Publishers. pp. 431-50, 2000.

BALANDIER, G. L'Afrique ambiguë (Ambiguous Africa). Paris, Plon, 1957.

The Colonial Situation: A Theoretical Approach. In: Social Change: the Colonial Situation, edited by I. WALLERSTEIN. New York, John Wiley and Sons, [1951] 1966, pp. 34-61

BLUMER, H. Symbolic Interactionism. Englewood Cliffs, NJ, Prentice-Hall, 1969.

BOURDIEU, P. Sociologie de l'Algérie (The Sociology of Algeria). Paris, Presses Universitaires de France, 1958.

. Le choc des civilisations (The Clash of Civilizations). In : Le Sous-Développement en Algérie, edited by SECRÉTARIAT SOCIAL D’ALGER. Algiers, Secrétariat social, 1959, pp. 52-64.

. The Algerians. Boston, Beacon Press, [1958] 1961.

. Champ intellectuel et projet créateur (Intellectual Field and Creative Project).

Les Temps Modernes, v. 22, 1966, pp. 865-906.

Les conditions sociales de la production sociologique: sociologie coloniale et décolonisation de la sociologie (The Social Conditions of Sociological Production: Colonial Sociology and the Decolonization of Sociology). In: Le Mal de Voir. Paris, Union Générale d’Éditions, pp. 416-27, 1975.

. Outline of a Theory of Practice. Cambridge, UK, Cambridge University Press, 1977.

Algeria 1960. Cambridge, UK, Cambridge University Press, [1963] 1979.

. Distinction: A Social Critique of the Judgement of Taste. Cambridge, MA, Harvard University Press, 1984.

. Homo Academicus. Cambridge, UK, Polity, 1988.

The Logic of Practice. Palo Alto, CA, Stanford University Press, 1990a.

In Other Words: Essays towards a Reflexive Sociology. Stanford, CA, Stanford University Press, 199ob. 
Pour Abdelmalek Sayad (For Abdelmalek Sayad). Annuaire de l'Afrique du

Nord, $v$ 37, 1998, pp. 9-12.

. Entre amis (Friends). Awal, v. 2, 2000, pp. 5-10.

Foreword. In: Uncivil war: Intellectuals and Identity Politics, edited by J. D. Le

Sueur. Philadelphia, University of Pennslvania Press, 2001, pp. ix-x.

Picturing Algeria. New York, Columbia University Press. 2003.

. Esquisses Algériennes (Algerian Sketches). Paris, Éditions du Seuil, 2008a.

Sketch for a Self-analysis. Chicago, University of Chicago Press, $2008 \mathrm{~b}$.

BOURDIEU, P.; DERBEL, A.; RIVET, J.-P.; SEIBEL, C. Travail et travailleurs en Algérie

(Work and Workers in Algeria). Paris, Mouton, 1963.

BOURDIEU, P.; ROBBINS, D.; GOMME, R. Colonialism and Ethnography: Foreword

to Pierre Bourdieu's. Travail et travailleurs en Algérie. Anthropology Today, v. 19, 2003, pp.12-8.

BOURDIEU, P. ; SAYAD, A. Le Déracinement. La Crise de l'Agriculture Traditionnelle

en Algérie (The Uprooting: The Crisis of Traditional Agriculture in Algeria). Paris:

Minuit, 1964

CÉSAIRE, A. Discourse on Colonialism. Translated by Joan Pinkham. New York, Monthly Review Press, 1955.

CONKLIN, A. The New 'Ethnology' and 'La Situation Coloniale' in Interwar France.

French Politics, Culture and Society, v. 20, pp. 29-46, 2002

CONNELL, R. Southern Theory. Cambridge: Polity Press, 2007.

COOPER, F. Decolonizing Situations: The Rise, Fall and Rise of Colonial Studies, 1951-

2001. French Politics, Culture and Society, v. 20, 2002, pp. 47-76.

FANON, F. A Dying Colonialism. New York, Grove Press, [1959] 1965.

Black Skin, White Masks. New York, Grove Press, [1952] 1967.

. The Wretched of the Earth. New York, Grove Press, [1961] 1968.

GANDHI, L. Postcolonial Theory. New York, Columbia University Press, 1998.

GO, J. Postcolonial Thought and Social Theory. New York, Oxford University Press, 2016

HADDOUR, A. Torture Unveiled: Rereading Fanon and Bourdieu in the Context of May 1958. Theory, Culture and Society, v. 27, 2010, pp. 66-90.

HEILBRON, J. Practical Foundations of Theorizing in Sociology: The Case of Pierre Bourdieu. In: Social Knowledge in the Making, edited by C. Camic, N. Gross, and M. Lamont. Chicago: University of Chicago Press, 2011, pp. 181-205.

LANE, C. Psychoanalysis and Colonialism Redux: Why Mannoni's 'Prospero Complex' Still Haunts Us. Journal of Modern Literature, v. 25, 2002, pp. 127-50.

LEIRIS, M. L'ethnographe devant le colonialisme (The Ethnographer before Colonialism).

Les Temps Modernes, v. 58, pp. 83-112, 1950. 
LE SUEUR, J. D. Uncivil War: Intellectuals and Identity Politics during the Decolonization of Algeria. Philadelphia, University of Pennsylvania Press, 2001.

LOYAL, S. The French in Algeria, Algerians in France: Bourdieu, Colonialism and Migration. The Sociological Review, v. 57, 2009, pp. 406-27.

MANNONI, O. Prospero and Caliban: The Psychology of Colonization. New York, Frederick A. Preager, [1950] 1964.

MEMMI, A. The Colonizer and the Colonized. Boston, Beacon Press, [1957] 1965.

MIGNOLO, W. Epistemic disobedience, independent thought and decolonial freedom.

Theory, Culture \& Society, v. 26, 2009, pp. (7-8):159.

SAADA, E. Regards Croisés: Transatlantic Pespectives on the Colonial Situation. French

Politics, Culture and Society, v. 20, 2002, pp. 1-3.

REDFIELD, R.; LINTON, R.; HERSKOVITS, M. J. Memorandum for the Study of Acculturation. American Anthropologist, v. 38, 1936, pp. 149-52.

ROBBINS, B. The Origins, Early Development and Status of Bourdieu's Concept of

'Cultural Capital'. British Journal of Sociology, v. 56, 2005, pp. 13-30.

SAID, E. Representing the Colonized: Anthropology's Interloctors. Critical Inquiry, $v$. 15, 1989, pp.205-25.

SALLAZ, J. J.; ZAVISCA, J. Bourdieu in American Sociology, 1980-2004. Annual Review of Sociology, v. 33, 2007, 21-41.

SAYAD, A. Histoire et Recherche Identitaire (History and Identity Research). Saint-

Denis, France, Editions Bouchene, 2002.

SEIBEL, C. "Les liens entre Pierre Bourdieu et les statisticiens à partir de son expérience algérienne" (Links between Pierre Bourdieu and Statisticians during His Algerian Experience). In : La Liberté par la Connaissance: Pierre Bourdieu (1930-2002), edited by J. Bouveresse and D. Roche. Paris: Odile Jacob, 2004, pp. 105-19.

SORUM, P. C. Intellectuals and Decolonization in France. Chapel Hill, University of North Carolina Press, 1977.

STEINMETZ, G. 2011. "Bourdieu, Historicity, and Historical Sociology." Cultural Sociology, 5:45-66.

SWARTZ, D. 1997. Culture and Power: The Sociology of Pierre Bourdieu. Chicago: University of Chicago Press.

TILLION, G. L’Algérie en 1957 (Algeria 1957). Paris, Éditions de minuit, 1958.

WACQUANT, L. Bourdieu in America: Notes on the Transatlantic Importation of Social

Theory. In: Bourdieu: Critical Perspectives, edited by C. Calhoun, E. LiPuma, and

M. Postone. Chicago, University of Chicago Press, 1993, pp. 235-62.

Following Pierre Bourdieu into the Field. Ethnography, v. 5, 2004, pp. 387-414.

WILDER, G. Colonial Ethnology and Political Rationality in French West Africa.

History and Anthropology, v. 14, 2003, pp. 219-52. 
YACINE, T. Hommage à Mouloud Mammeri (Homage to Mouloud Mammeri). Paris, Editions de la Maison des Sciences de l'Homme, 1990. . L’Algérie, matrice d'une oeuvre (Algeria: A Matrix of Work). In : Travailler avec Bourdieu, edited by P. Encrevé and R. M. Lagrave. Paris, Flammarion. 2003a, pp. 333-45.

Du proletariat et de la paysannerie en Algérie. Pour une archéologie de la domination symbolique (The Proletariat and the Peasantry in Algeria. For an Archeology of Symbolic Domination). In: L'Anthropologie du Maghreb selon Berque, Bourdieu, Geertz et Gellner, edited by L. Addi. Paris: Ibis Press, 2003b, pp. 179-93. Pierre Bourdieu in Algeria At War: Notes on the Birth of an Engaged Ethnosociology. Ethnography, v. 5, 2004, pp. 487-509.

. Bourdieu et l'Algérie: La réception internationale de la pensée de Pierre Bourdieu (Bourdieu and Algeria: The International Reception of the Thought of Pierre Bourdieu). In : Le symbolique et le social, edited by J. Dubois, P. DURAND, and Y. WINKIN. Liège: Les editions de l'Université de Liège. 2005, pp. 33-51

. Aux origines d'une ethnosociologie singulière (The Origins of a Singular Ethnosociology). In : Pierre Bourdieu, Esquisses Algériennes, edited by T. Yacine. Paris: Éditions du Seuil, 2008a, pp. 23-53.

Le projet éditorial (The Editorial Project). In : Pierre Bourdieu, Esquisses Algériennes, edited by T. Yacine. Paris: Éditions du Seuil, 2008b, pp. 11-20.

Recebido em 21/12/2017

Aprovado em 19/02/2018

\section{Como citar este artigo:}

GO, Julian. Bourdieu, Argélia e a Perspectiva Pós-Colonial. Contemporânea - Revista de Sociologia da UFSCar, v. 8, n. 1, jan.- jun. 2018, pp 11-32. 